\title{
Influence of Use of Insole on Blood Glucose Rate Diabetes Mellitus Type-2
}

\author{
Ignatius Heri Dwianto ${ }^{1}$ Bambang Purwanto ${ }^{2}$ and Sony Wibisono ${ }^{3}$ \\ ${ }^{1}$ Sports Health Sciences Faculty of Medicine, Airlangga University, Jl. Prof Moestopo 47. Surabaya, Indonesia \\ ${ }^{2}$ Department of Physiology Faculty of Medicine, Airlangga University, Surabaya, Indonesia \\ ${ }^{3}$ Department of Internal Medicine Dr. Soetomo Surabaya, Indonesia \\ heri594@yahoo.co.id
}

Keywords: Diabetes Mellitus, Eccentric Strain, Fasting Blood Glucose, Insole, Postprandial Blood Glucose.

\begin{abstract}
Background: Tiptoeing is not easy to do continuously and, in the long term, tiptoe can be replaced by the use of insole. The use of insole at $-10^{\circ}$ angle for five days in healthy subjects has been proven to decrease fasting blood glucose levels and improve glucose tolerance in hyperglycemia patients. Objectives: This study is aimed prove the effect of insole use on the decrease of fasting blood glucose and postprandial blood glucose level after the use of insole in type 2 diabetes mellitus. Methods: Design of this study is pre and post-test with control and respondents of this study being people with diabetes mellitus type 2 divided into two groups in Paguyuban Diabetes and Hidup Sehat of "X" Hospital Surabaya. The treatment lasted for five days by providing shoes with insole- $10^{\circ}$ for one group while the other group's shoes were not provided with any. Subjects' blood from both groups was tested prior to treatment as well as post-treatment. Result: The result of data analysis of fasting blood glucose level in group with insole $0^{\circ}$ using paired t-test shows $p$ value 0.494 while the other group with insole $10^{\circ}$ has $\mathrm{p}$ value 0.022 . The blood glucose level two hours postprandial in the group with shoes with insole $0^{\circ}$ has $\mathrm{p}$ value 0.082 and the group with shoes with insole $10^{\circ}$ has $\mathrm{p}$ value 0.016 . The use of shoes with insole $-10^{\circ}$ for five days has an effect on decreasing fasting blood glucose and blood glucose level two hours postprandial. Conclusions: The results of this study were the use of insole $-10^{\circ}$ decreased fasting blood glucose level and postprandial blood glucose level in type 2 diabetes mellitus and there was a difference of effect of insole -10 and flat insole $\left(0^{\circ}\right)$ on fasting blood glucose level and postprandial blood glucose level in type 2 diabetes mellitus.
\end{abstract}

\section{INTRODUCTION}

One of the functions of the insole is used to provide comfort and protect the foot from trauma micro in diabetic condition and can be used to help improve the position of the foot and ankle and adjust the loading on the foot (Uccioli \& Giacomozzi 2009). The results of the previous study stated that the use of insole with the angle of $-10^{\circ}$ for five days in healthy subjects decreased fasting blood glucose levels and improved glucose tolerance in patients with hyperglycaemia (Kusuma et al. 2016). By stimulating the expression of GLUT-1 it potentially helps to improve insulin sensitivity, which is impaired in type 2 diabetics (Rehman et al. 2012). To date, the effect of insole on blood glucose level of diabetes mellitus has not been proven.

Diabetes mellitus is a major health problem. Current epidemiological studies have shown an increasing trend in incidence rates and the prevalence of type 2 diabetes mellitus in different parts of the world. The World Health Organization (WHO) predicts an increase in the number of people with Diabetes Mellitus (DM) in Indonesia from 8.4 million in 2000 to about 21.3 million in 2030 (Kpozehouen et al. 2015), while the International Diabetes Federation (IDF 2015) predicts an increase in the number of people with DM in Indonesia from 9.1 million in 2014 to 14 million in 2035 .

Several earlier studies have shown that eccentric strain can affect glucose uptake. In vitro trial, m. gastrocnemius can be stretched eccentrically up to $130 \%$ of the initial length, incorporated into glucosediluted thyrode. The result is no muscle damage with a greater muscle contraction response and glucose uptake is also increased (Purwanto 2016). Eccentric strain due to the influence of insole use at $-10^{\circ}$ angle for five days in healthy subjects decreased 
fasting blood glucose (Kusuma et al. 2016). Until now, the influence of insole use on blood sugar level of diabetes mellitus has not been proven.

The purpose of this study proves the effect of insole use on decreased blood glucose levels in people with type 2 diabetes mellitus

\section{METHODS}

This research is a type of experimental research, with pre and post-test design with control design. The data were collected in the Diabetes Society and Healthy Life Hospital "X" Surabaya. Subjects in this study were diabetics who met the inclusion criteria of male and female sex, age 50-70 years, Fasting Blood Glucose (GDP) more or equal to $126 \mathrm{mg} / \mathrm{dl}$ (126mg / dl - 199mg / dl), no ulcus in the foot and willing to follow the protocol during the study while the exclusion criteria were foot ulcus, muscle spasm / injury to the gastrocnemius muscle. The sampling technique used individuals having the appropriate criteria as a simple randomized experimental unit to be selected as an experimental unit.

This study was conducted after obtaining a research permit from the Director of Catholic Hospital "X" Surabaya and receiving informed consent signed by the respondents. Subjects selected as respondents were measured for foot size for insole and shoe design. Subjects were divided into two groups, the shoe user group without insole as group 1 and the shoe group with insole $-10^{\circ}$ as group 2. Further measurements of fasting blood glucose and postprandial blood glucose levels were taken before wearing shoes without insole and shoes with insole for both groups. Subjects in group 1 who were measured blood glucose levels then wore shoes without insole every day for 8 hours / day for five days. Subjects in group 2 who were measure for blood glucose levels then wore shoes with insole every day for 8 hours / day for five days. After five days, both group 1 and group 2 were re-examined for fasting blood glucose level and postprandial blood glucose level. Further data were collected and analyzed statistically.

\section{RESULTS}

Descriptive analysis of the characteristics of the study subjects depicted mean and standard intersection of age, height, weight, BMI, fasting blood glucose and blood glucose level two hours postprandial (pre and post-test) with the use of shoes with insole $0^{\circ}$ and fasting glucose and blood glucose levels two hours postprandial (pre and post-test) with the use of shoes with insole -10. Data are presented in Table 1.

\begin{tabular}{ccc}
\hline \multirow{2}{*}{ Variables } & \multicolumn{2}{c}{ Average \pm SD } \\
\cline { 2 - 3 } & Insole group $0^{0}$ & Insole group10 \\
\hline Age (year) & $63.62 \pm 2.97$ & $63.50 \pm 4.62$ \\
Height (cm) & $160.50 \pm 5.18$ & $159,50 \pm 6.36$ \\
Weight (kg) & $59.75 \pm 4.49$ & $59.62 \pm 4.83$ \\
BMI & $22.75 \pm 1.48$ & $23.00 \pm 1.51$ \\
GDP(pre) & $168.87 \pm 50.54$ & $170.37 \pm 50.42$ \\
GDP(post) & $180.12 \pm 46.50$ & $143.50 \pm 56.45$ \\
GD 2jpp (pre) & $247.37 \pm 65.90$ & $252.25 \pm 67.13$ \\
GD 2jpp (post) & $294.12 \pm 58.29$ & $218.37 \pm 66.57$ \\
N & \multicolumn{2}{c}{8} \\
\hline Description: GDP (fasting blood glucose), GD 2jpp (blood \\
glucose two hours postprandial).
\end{tabular}

Table 2 and Table 3 illustrate different tests of fasting blood glucose level and blood glucose level two hours postprandial pre and post use of shoes with insole $0^{\circ}$ and shoes with insole $10^{\circ}$ each group using paired $t$ test

Table 2: Group shoes with insole $0^{0}$.

\begin{tabular}{ccccc}
\hline \multirow{2}{*}{ Variable } & \multirow{2}{*}{$\mathrm{N}$} & \multicolumn{2}{c}{$\begin{array}{c}\text { Average } \pm \text { SD } \\
\text { Insole group } 0^{0}\end{array}$} & $\mathrm{P}$ \\
\cline { 3 - 4 } & & Pre & \multicolumn{2}{c}{ Post } \\
\hline GDP & 8 & $168.87 \pm 50.54$ & $180.12 \pm 46.50$ & 0.494 \\
GDP 2jpp & 8 & $250.50 \pm 62.71$ & $291.00 \pm 64.18$ & 0.082 \\
\hline
\end{tabular}

Table 3: Group shoes with insole $-10^{\circ}$.

\begin{tabular}{ccccc}
\hline \multirow{2}{*}{ Variable } & \multirow{N}{*}{} & \multicolumn{2}{c}{$\begin{array}{c}\text { Average } \pm \text { SD } \\
\text { Insole group }-10^{0}\end{array}$} & \multirow{2}{*}{$\mathrm{P}$} \\
\cline { 3 - 4 } & & Pre & Post & \\
\hline GDP & 8 & $170.37 \pm 50.42$ & $143.62 \pm 56.73$ & 0.022 \\
GD 2jpp & 8 & $255.75 \pm 64.58$ & $214.87 \pm 66.98$ & 0.016 \\
\hline
\end{tabular}

$P$ value $<0.05$ indicates a meaningful effect. The use of shoes with insole $-10^{\circ}$ for five days has an effect on decreasing fasting blood glucose and blood glucose level two hours postprandial.

Table 4 illustrates the mean values and standard deviations of the delta of fasting blood glucose in the two groups.

\begin{tabular}{ccc}
\hline \multirow{2}{*}{ Variables } & $\begin{array}{c}\text { Treatment of Insole } 0^{0} \\
\text { dan insole }-10^{0}\end{array}$ & \multirow{2}{*}{ Value of $\mathrm{P}$} \\
\cline { 2 - 3 } & Average $\pm \mathrm{SD}$ & \\
\hline$\Delta$ GDP & $-7.81 \pm 40.05$ & 0.053 \\
$\Delta$ GD 2jpp & $6.43 \pm 61.91$ & 0.004 \\
\hline
\end{tabular}


Based on the above data, it can be concluded that the use of insole causes a decrease in blood glucose levels two hours postprandial compared with decreased fasting blood glucose levels.

\section{DISCUSSION}

The use of shoes with insole $-10^{0}$ in type 2 diabetes mellitus in this study had a significant effect on fasting blood glucose level. The results of previous study stated that the use of insole with the angle of $10^{\circ}$ for five days in healthy subjects decreased fasting blood glucose levels and improved glucose tolerance in patients with hyperglycaemia (Kusuma et al. 2016). The use of shoes with insole $-10^{\circ}$ causes strain on the calf muscle (m.gastrocnemius, m.soleus and m.plantaris). The response of this muscle strain is the eccentric contraction to prevent tearing of the muscles by recompiling the origo (Purwanto 2016). The eccentric contraction causes actin and myosin cross bridges to drift apart, so that sarcoplasmic sarcars and reticulum are elongated. The elongation of this sarcoplasmic reticulum causes $\mathrm{Ca} 2+$ ions to be excreted (Guyton n Hall 2011). Ca2 + ion expenditure causes muscle contraction; the longer the muscle is stimulated to create an eccentric strain, the longer the muscle contraction response occurs. This causes the body to need more energy, but also causes ischemic repercussion stress, wherein blood vessels narrow and widen repeatedly, creating blood flow turbulence and local hypoxia to occur. Hypoxic conditions increase the formation of GLUT 1, so the GLUT 1 expression on the plasma membrane increases (Ciaraldi 2007). This increase in GLUT 1 increases glucose uptake into cells for use in glycolytic reactions that produce energy, so that the energy requirements of the muscle calf to maintain body position can be met (Purwanto 2016). The increased glucose uptake by GLUT 1 for the glycolysis process lowers fasting glucose levels.

The use of shoes with insole $-10^{\circ}$ in type 2 diabetes mellitus in this study also gave a significant effect on blood glucose level two hours postprandial. Research conducted by Rose and Rithcer (Effendi, Santoso, \&Purwanto 2009), showed that, in experimental animals as well as in humans, there was increased glucose uptake in skeletal muscle; the higher the intensity of exercise, the more glucose that goes into the skeletal muscle cells. Handoko (2017) found eccentric exercise can reduce blood glucose levels and increase levels of glucose transporter protein in muscle of diabetic rats and concluded that giving single eccentric exercises in decreased ways can increase blood glucose levels due to increased levels of GLUT-1 and GLUT-4 protein

Insulin is the only hormone that can lower blood glucose levels. The transport of glucose between blood and cells is carried out by a plasma membrane carrier known as a glucose transporter (GLUT) (Sherwood, 2009). Skeletal muscle is the main organ in which insulin-mediated glucose is absorbed. Adipose tissue has a smaller role. Insulin binds to the skeletal muscle plasma membrane, which is bound to the receptor, which activates the phosphorylative function. This triggers the cascade of the specific tyrosine residue of signaling proteins, down some of the insulin receptor substrate (IRS1 is the main isoform in muscle) through phosphotidylinositol 3 kinase (PI3 kinase) to Akt (also known as Akt / protein kinase B, or Akt / $\mathrm{PKB}$ ). The phosphorylation of these proteins causes GLUT-4 to migrate from intracellular vesicles to the plasma membrane, thereby facilitating the entry of glucose into the cell. The postprandial condition of insulin will increase the absorption of blood glucose by skeletal muscle (and at low levels by adipose tissue) and gradually restore glucose blood at fasting level.

Expression and function of GLUT-4 can be seen from examination of glucose level two hours postprandial. After eating, blood glucose levels increase, and this will stimulate the secretion of insulin from the pancreatic beta cells. The decrease in GLUT-4 expression will correlate with an increase in glucose levels of two hours postprandial (Purwanto 2016).

The use of insole causes a decrease in blood glucose levels two hours postprandial compared with decreased fasting blood glucose levels. This result is caused by postprandial condition, which regulates regulation of blood glucose level in insulin. Insulin sensitivity is affected when eccentric exercise or insole use is performed at least twice a week. Regular exercise can lead to multiple muscle adaptation processes, such as being able to produce ATP more efficiently, so that muscles are more resistant to fatigue, increased activity and amount of mitochondria, and increased muscle responsiveness to insulin by increasing the expression and activity of proteins that play a role in glucose metabolism and insulin signaling (Colberg , 2010)

One of the proteins that play a role in glucose metabolism is GLUT-4. GLUT-4 is the main glucose transporter that carries glucose from the blood into the cells to maintain the balance of glucose levels. Increased concentration and activity 
of GLUT-4 is in response to regular exercise, which plays a role in facilitating glucose uptake in the muscles trained during the exercise process. Muscle contractions produced during eccentric exercise can occur due to the interaction process between actin and myosin. The process of this interaction occurs because of calcium ions in muscle cells. The calcium ion will activate calcium / calmodulin-dependent protein kinase $(\mathrm{CaMK})$, which then activates protein kinase A (PKA), and the active PKA will play a role in GLUT-4 transplantation into the cell membrane (Jensen \& Richter 2012).

During exercise, energy generation will be lower than energy use, depending on the intensity of the exercise being performed. This will lead to a decrease in creatine phosphate and ATP concentrations, while AMP concentrations continue to increase. Changing this condition will activate AMP-activated protein kinase (AMPK). Increasing the activity of CaMK and AMPK will increase the concentration of GLUT-4. Giving gymnastics can decrease blood glucose levels two hours postprandial, but it is not significant. This is suspected because the revitalization of GLUT-4 melui increasing ATP by GLUT-1 is not enough to lower blood glucose levels significantly (Chung et al. 2009; Handoko 2017). Expression and function of GLUT-4 can be seen from examination of glucose level two hours postprandial. After eating, blood glucose levels increase and this will stimulate the secretion of insulin from the pancreatic beta cells. The decrease in GLUT-4 expression will correlate with an increase in glucose levels of two hours postprandial (Purwanto 2016).

There are some limitations in this research, namely: activity of research subject which cannot be controlled and intake of food given to research subject cannot be controlled. Body Mass Index (BMI) is also uncontrolled in this research because BMI in both groups before treatment was not significantly different, so future research of BMI subjects need to be controlled to know the effectiveness of shoe insole usage on subjects having BMI greater than the subjects in this study. The consumption of drugs used in research subjects is not the same, so that may affect the results of research and use of shoes with insole for eight hours is difficult to be controlled, so that it may affect the results of the research.

\section{CONCLUSION}

The results of this study were the use of insole $-10^{\circ}$ decreased fasting blood glucose level and postprandial blood glucose level in type 2 diabetes mellitus and there was a difference of effect of insole -10 and flat insole $\left(0^{0}\right)$ on fasting blood glucose level and postprandial blood glucose level in type 2 diabetes mellitus.

\section{REFERENCES}

Chung, Y. et al., 2009. Regulation of Glucose Transporter 1 by IL-1 $\beta$ Stimulation in Rat Articular Chondrocytes. ,29(3), pp.125-130.

Ciaraldi, T.P., 2007. GSK-3ß and Control of Glucose Metabolism and Insulin Action in Human Skeletal Muscle.

Colberg, et al, 2010. Exercise and Type 2 Diabetes., 33(12).

Effendi, C., Santoso, K.P., Purwanto, B., 2009. Buku Ajar Faal Sel, Cair Tubuh, Saraf Tepi, dan Otot.

Guyton A C dan Hall J E, 2011. Fisiologi kedokteran dua belas., Singapura: Elseiver.

Handoko, A., 2017. Pengaruh aktivitas eksentrik terhadap kadar glucose transporter-1 dan glucose transporter-4 pada otot gastroknemius mencit diabetes melitus yang diinduksi streptozotocin.

IDF, 2015. DIABETES,

Jensen, T.E. \& Richter, E.A., 2012. Regulation of glucose and glycogen metabolism during and after exercise. , 5(March), pp.1069-1076.

Kpozehouen, A. et al., 2015. Prevalence and Associated Factors of Diabetes Mellitus in Benin., (August), pp.163-171.

Kusuma, H., Abdullah, A. \& Purwanto, B., 2016. Insole Inclination of Work Shoes Decrease Fasting Blood Glucose and HbA1c Level. jurnal Ners, 11.

Purwanto, B., 2016. Kontraksi Eksentrik Respon Fisiologis Otot Mencegah Kerusakan, PT REVKA PETRA MEDIA, 2016.

Rehman, A.U., Siddiqui, M.A. \& Ashraff, S., 2012. Effect of Exercise and Muscle Contraction on Insulin Action , Transportation and Sensitivity and Muscle Fibres in type II Diabetes Mellitus. , 2(6), pp.2-6.

Uccioli, L. \& Giacomozzi, C., 2009. Biomechanics and choosing footwear for the diabetic foot. The Diabetic Foot Journal, 12(4). 